Article

\title{
Fine Crystalline Mg-Al Hydrotalcites as Catalysts for Baeyer-Villiger Oxidation of Cyclohexanone with $\mathrm{H}_{2} \mathrm{O}_{2}$
}

\author{
Robert Karcz *D, Bogna D. Napruszewska, Alicja Michalik, Joanna Kryściak-Czerwenka D, Dorota Duraczyńska \\ and Ewa M. Serwicka (D)
}

check for

updates

Citation: Karcz, R.; Napruszewska, B.D.; Michalik, A.;

Kryściak-Czerwenka, J.; Duraczyńska, D.; Serwicka, E.M. Fine Crystalline Mg-Al Hydrotalcites as Catalysts for Baeyer-Villiger Oxidation of Cyclohexanone with $\mathrm{H}_{2} \mathrm{O}_{2}$. Catalysts 2021, 11, 1493. https://doi.org/ $10.3390 /$ catal11121493

Academic Editor: Helder T. Gomes

Received: 25 November 2021

Accepted: 6 December 2021

Published: 8 December 2021

Publisher's Note: MDPI stays neutral with regard to jurisdictional claims in published maps and institutional affiliations.

Copyright: (c) 2021 by the authors. Licensee MDPI, Basel, Switzerland. This article is an open access article distributed under the terms and conditions of the Creative Commons Attribution (CC BY) license (https:// creativecommons.org/licenses/by/ $4.0 /)$.
Jerzy Haber Institute of Catalysis and Surface Chemistry, Polish Academy of Sciences, Niezapominajek 8, 30-239 Krakow, Poland; ncnaprus@cyf-kr.edu.pl (B.D.N.); ncmichal@cyf-kr.edu.pl (A.M.); nckrysci@cyf-kr.edu.pl (J.K.-C.); dorota.duraczynska@ikifp.edu.pl (D.D.); ncserwic@cyf-kr.edu.pl (E.M.S.)

* Correspondence: robert.karcz@ikifp.edu.pl; Tel.: +48-12-6395-164

Abstract: The catalytic activity of Mg-Al hydrotalcite (HT) materials in base-catalyzed reactions is known to be promoted by the low crystallinity of the HT solid. In the present work, two routes enabling the preparation of finely crystalline $\mathrm{Mg}-\mathrm{Al} \mathrm{HT}$ materials were explored: (1) the inverse microemulsion technique, and (2) co-precipitation in the presence of starch. Carbonate, chloride and bromide forms of HT were prepared, examined with X-ray diffraction, scanning electron microscopy/energy dispersive X-ray spectroscopy and infrared spectroscopy, and used as catalysts in the Baeyer-Villiger oxidation of cyclohexanone to $\varepsilon$-caprolactone with a $\mathrm{H}_{2} \mathrm{O}_{2}$ /acetonitrile system. The bromide forms proved significantly less active than the chlorides and carbonates, as they promoted nonselective consumption of $\mathrm{H}_{2} \mathrm{O}_{2}$. The fine crystalline materials were more active than the more crystalline HT references obtained by conventional co-precipitation. Catalysts prepared by inverse microemulsion were less crystalline and more active than the starch-templated ones, but suffered stronger deactivation by the acidic reaction environment. Alkalization of the reaction medium with $\mathrm{NaHCO}_{3}$ stabilized the HT materials and increased the $\varepsilon$-caprolactone yield, which became comparable for both types of fine crystalline catalysts - thus pointing to the synthesis involving a simple and cheap starch templating approach as being a particularly attractive one.

Keywords: hydrotalcite; crystallinity; inverse microemulsion; starch biotemplate; Baeyer-Villiger oxidation; $\mathrm{H}_{2} \mathrm{O}_{2}$ oxidant; cyclohexanone; $\varepsilon$-caprolactone; bicarbonate-activated $\mathrm{H}_{2} \mathrm{O}_{2}$

\section{Introduction}

Hydrotalcite (HT) is a naturally occurring layered mineral, with the formula $\mathrm{Mg}_{6} \mathrm{Al}_{2}(\mathrm{OH})_{16} \mathrm{CO}_{3} \cdot 4 \mathrm{H}_{2} \mathrm{O}$. It is structurally related to another layered mineral, brucite $\left(\mathrm{Mg}(\mathrm{OH})_{2}\right)$, composed of stacked layers of edge-sharing octahedra, with $\mathrm{Mg}^{2+}$ in the center and $\mathrm{OH}^{-}$groups in the corner positions. In $\mathrm{HT}$, one $\mathrm{Mg}^{2+}$ is substituted with $\mathrm{Al}^{3+}$, which results in a net positive charge of the layer, so that electroneutrality is ensured by the presence of anions in the interlayer. In natural HT, this layer charge is compensated for by carbonate anions. The interlayer also contains water of crystallization (Figure 1) [1]. HT and HT-like compounds, with the general formula $\left(\mathrm{M}^{2+}{ }_{1-\mathrm{x}} \mathrm{M}^{3+}{ }_{\mathrm{x}}(\mathrm{OH})_{2}\right)^{\mathrm{x}+}\left(\mathrm{A}^{\mathrm{n}-} \mathrm{x} / \mathrm{n}\right) \cdot m \mathrm{H}_{2} \mathrm{O}$, where $\mathrm{M}^{2+}$ and $\mathrm{M}^{3+}$ are the layer forming di- and trivalent cations, and $\mathrm{A}^{\mathrm{n}-}$ is the interlayer anion, can be easily synthesized in the laboratory [2].

Synthetic Mg-Al HT materials are commonly used in heterogeneous catalysis as solid base catalysts, or catalyst precursors, for a number of reactions, e.g., aldol and Knoevenagel condensations, transesterification of oils, isomerization of sugars or synthesis of organic intermediates [3-22]. One of the most studied catalytic reactions using Mg-Al $\mathrm{HT}$ as a catalyst is the liquid phase Baeyer-Villiger (B-V) oxidation of cyclohexanone to $\varepsilon$-caprolactone [23-32], a monomer used for the production of polycaprolactone, a biodegradable and biocompatible polymer [33,34]. 


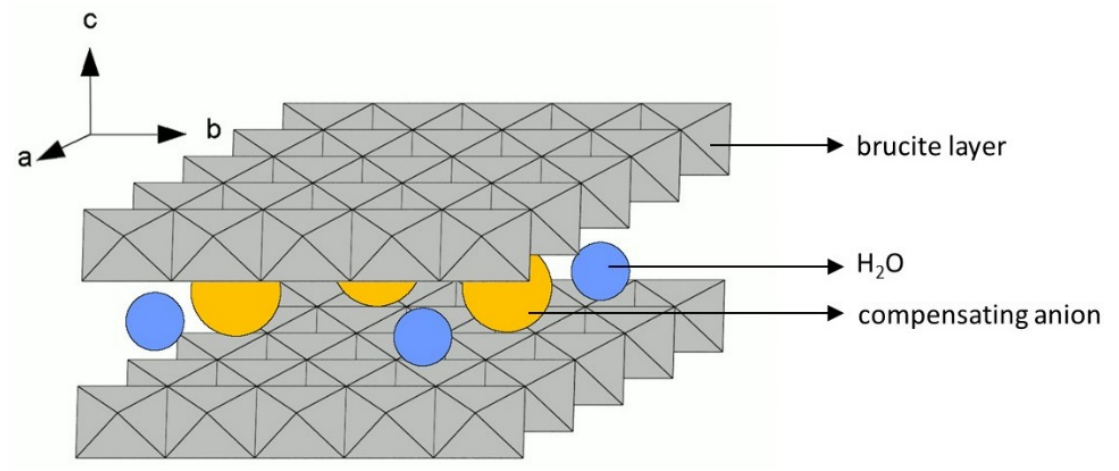

Figure 1. Schematic illustration of HT structure.

It has been repeatedly demonstrated that diminution of Mg-Al HT crystal size, usually achieved by the variation of synthesis parameters such as, e.g., temperature, degree of supersaturation of reactants, aging time, use of sonication, etc., favorably influences the catalytic performance $[5-8,13,14,31]$. Therefore, studies into methods for synthesizing smaller HT crystallites are beneficial for designing more efficient catalysts.

In the present work, two synthetic routes enabling the preparation of finely crystalline $\mathrm{Mg}-\mathrm{Al} \mathrm{HT}$ materials, as yet not tested in the preparation of catalysts for base-catalyzed reactions, were explored: (1) synthesis by means of inverse microemulsion technique (referred to as HT/im), and (2) co-precipitation in the presence of biopolymer (starch) as a medium restraining the growth of crystallites (referred to as HT/s). The use of an inverse microemulsion approach (also described as the water-in-oil microemulsion method) yields nanoparticles, whose dimensions are limited by the size of micelles acting as nanoreactors for material synthesis $[35,36]$. We used this procedure to prepare small-crystalline $\mathrm{Mn}$ Al HT-like precursors for catalytic application in VOC combustion [37,38]. The active phase obtained in such a way was much more finely grained than the reference obtained by standard co-precipitation, and displayed much higher activity in the combustion of toluene. The use of starch to provide restraint for crystal growth during the co-precipitation reaction of Mg-Al HT was recently proposed by Michalik et al. [39]. This simple synthesis procedure was shown to produce a finely crystalline product at a much lower cost and with significantly less effort than the inverse microemulsion method. Both types of HT nanocatalyst synthesized in the present work were tested in the Baeyer-Villiger oxidation of cyclohexanone; one of the reactions was shown to be promoted by decreases in HT crystal size [31]. The results were referenced to the performance of the HT catalyst obtained by standard co-precipitation (HT/ref).

\section{Results and Discussion}

\subsection{Physicochemical Characterization}

The HT materials were synthesized with chloride, bromide or carbonate anions in the interlayer. The choice of bromide and chloride was the consequence of using CTABr and $\mathrm{CTACl}$ surfactants in the synthesis carried out by the inverse microemulsion method. The results of the elemental analysis showed that in all synthesized materials, the $\mathrm{Mg} / \mathrm{Al}$ ratio was close to the intended value of three (Table 1). In the case of the $\mathrm{Cl}$ and $\mathrm{Br}$-containing samples, the ratio of $\mathrm{Cl} / \mathrm{Al}$ or $\mathrm{Br} / \mathrm{Al}$ was close to one, which indicates that halides were the dominant interlayer species. Nevertheless, a clear trend pointing to a certain deficit of halides as compensating anions showed that contamination by foreign anions might have occurred during synthesis. This aspect was further addressed in the analysis of the FTIR spectra.

The XRD patterns of the carbonate, chloride and bromide forms of the synthesized HT solids are gathered in Figure 2a-c, respectively. Each set of diffractograms enabled a comparison of the structural characteristics of the HT prepared by different methods. The $\mathrm{d}_{003}$ interlayer distances determined for the synthesized HT materials are given in Table 1 . The observed values were consistent with those reported in the literature for carbonate, 
chloride and bromide forms of HT [40]. The value of the $\mathrm{d}_{003}$ basal spacing is dependent on the type of interlayer anions [2]. The carbonate anion assumes a flat lying position in the interlayer, and its height has been estimated to be around $0.309 \mathrm{~nm}[41]$. The $\mathrm{Cl}^{-}$and $\mathrm{Br}^{-}$ anions are spherical, and their sizes are 0.336 and $0.380 \mathrm{~nm}$, respectively [42]. The observed order of basal spacings determined for the synthesized samples was $\mathrm{d}_{003}\left(\mathrm{HT}-\mathrm{CO}_{3}\right)<\mathrm{d}_{003}$ $(\mathrm{HT}-\mathrm{Cl})<\mathrm{d}_{003}(\mathrm{HT}-\mathrm{Br})$, i.e., it roughly followed the size of the introduced interlayer anions.

Table 1. $\mathrm{Mg} / \mathrm{Al}$ ratio, $\mathrm{Cl}(\mathrm{Br}) / \mathrm{Al}$ ratio, basal spacing, and crystal sizes in the $\mathrm{c}$ and a direction of $\mathrm{HT}$ samples. In brackets, the $\mathrm{Cl}(\mathrm{Br}) / \mathrm{Al}$ ratio after reaction with added bicarbonate.

\begin{tabular}{cccccc}
\hline Sample & $\mathbf{M g} / \mathbf{A l}$ & $\mathbf{C l}(\mathbf{B r}) / \mathbf{A l}$ & $\mathbf{d}_{\mathbf{0 0 3}}[\mathbf{n m}]$ & $\mathbf{D}_{\mathbf{0 0 3}}$ [nm] & $\mathbf{D}_{\mathbf{1 1 0}}$ [nm] \\
\hline $\mathrm{HT}-\mathrm{CO}_{3} / \mathrm{im}$ & 2.94 & - & 0.777 & 5.2 & 11.7 \\
$\mathrm{HT}-\mathrm{CO}_{3} / \mathrm{s}$ & 3.08 & - & 0.775 & 7.1 & 13.5 \\
$\mathrm{HT}-\mathrm{CO}_{3} / \mathrm{ref}$ & 2.86 & - & 0.774 & 13.9 & 14.4 \\
$\mathrm{HT}-\mathrm{Cl} / \mathrm{im}$ & 3.06 & 0.78 & 0.791 & 6.6 & 13.4 \\
$\mathrm{HT}-\mathrm{Cl} / \mathrm{s}$ & 3.00 & $0.84(0.09)$ & 0.792 & 7.6 & 13.9 \\
$\mathrm{HT}-\mathrm{Cl} / \mathrm{ref}$ & 2.84 & 0.89 & 0.797 & 15.6 & 17.2 \\
$\mathrm{HT}-\mathrm{Br} / \mathrm{im}$ & 2.91 & 0.82 & 0.812 & 6.3 & 13.6 \\
$\mathrm{HT}-\mathrm{Br} / \mathrm{s}$ & 2.99 & $0.71(0.03)$ & 0.809 & 7.0 & 13.1 \\
$\mathrm{HT}-\mathrm{Br} / \mathrm{ref}$ & 2.83 & 0.88 & 0.812 & 15.3 & 17.3 \\
\hline
\end{tabular}

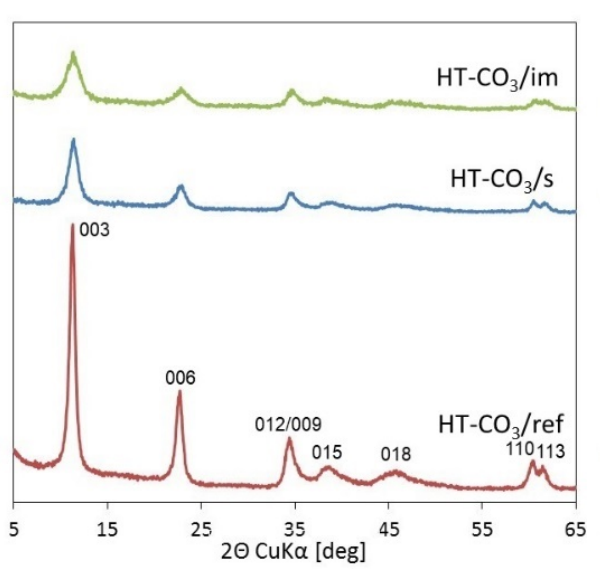

(a)

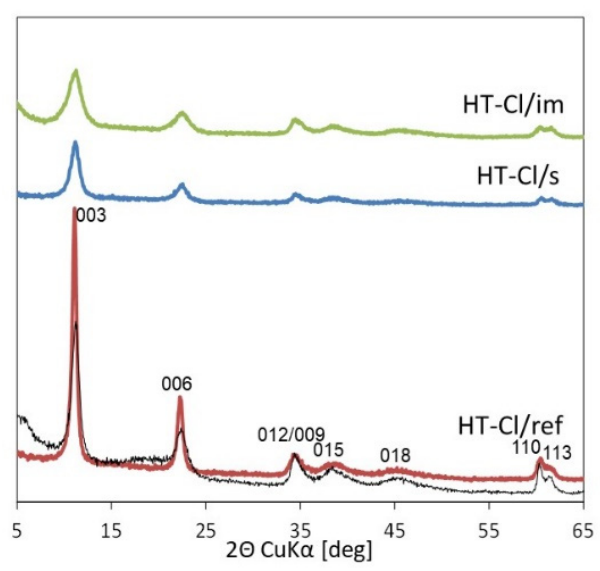

(b)

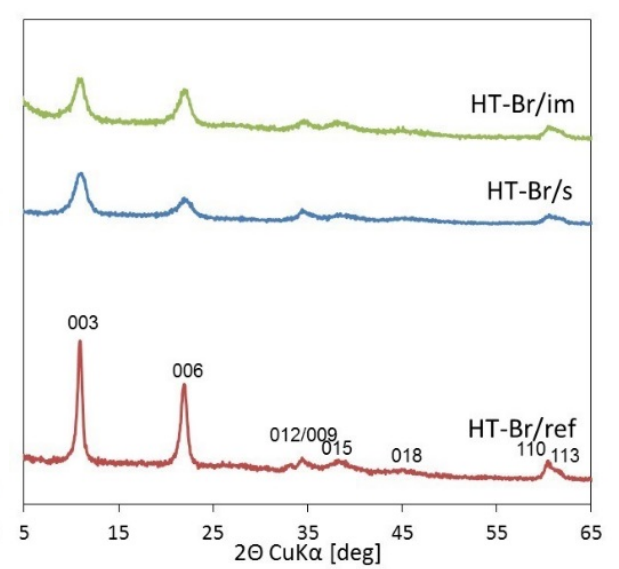

(c)

Figure 2. Powder XRD patterns of synthesized HT materials: (a) carbonate forms; (b) chloride forms (black trace—spent catalyst); (c) bromide forms.

For a given type of interlayer anion, the positions of the (003) reflexes were practically constant, as expected for similar degrees of Al-for-Mg substitution [43]. It was evident that in each case, the inverse microemulsion procedure and the starch-templated method resulted in materials with visibly broader reflections, indicating their lower crystallinity. The calculated crystal sizes in the $c\left(\mathrm{D}_{003}\right)$ and $a\left(\mathrm{D}_{110}\right)$ direction of the HT unit cell, estimated by analyzing the broadening of (003) and (110) reflections with the Scherrer equation, confirmed this conclusion (Table 1). Of the two preparative approaches aimed at the synthesis of fine crystalline HT materials, the one involving the formation of inverse microemulsion yielded, in general, somewhat smaller crystallites than the method based on the use of starch.

The FTIR spectra of the samples were characteristic of HT materials (Figure 3) [44]. The broad intense band centered around $3400-3500 \mathrm{~cm}^{-1}$ resulted from overlapping of the stretching vibrations of the layer hydroxyl groups and the stretches of interlayer water molecules. The shoulder around $3050 \mathrm{~cm}^{-1}$, visible in the spectra of the carbonate forms, was due to the $\mathrm{OH}$ stretches in water molecules hydrogen-bonding with interlayer carbonates. The band at ca. $1640 \mathrm{~cm}^{-1}$ was associated with the bending mode of the interlayer water. Of the chloride, bromide and carbonate interlayer anions, only the latter 
were expected to show IR absorptions. Accordingly, in the carbonate forms of HT, an intense band at ca. $1370 \mathrm{~cm}^{-1}$ due to the $v_{3}$ asymmetric CO stretch of the carbonate anions, and a shoulder at $1490 \mathrm{~cm}^{-1}$ related to the $v_{3}$ symmetric $C O$ stretch of the bicarbonate species, were observed. However, the FTIR spectra of all the chloride and bromide HT samples also indicated the presence of some carbonates. Besides this, in HT-Br/im and $\mathrm{HT}-\mathrm{Br} / \mathrm{s}$, the presence of a narrow band at $1385 \mathrm{~cm}^{-1}$, corresponding to the $v_{3}$ asymmetric stretch of $\mathrm{NO}_{3}{ }^{-}$, shows that not all nitrates were eliminated during synthesis. As far as carbonates are concerned, it is known that atmospheric $\mathrm{CO}_{2}$ is a frequent source of contamination by $\mathrm{CO}_{3}{ }^{2-}$ [45], both during synthesis and during storage. Thus, the FTIR analysis shows that the deficit of $\mathrm{Br}$ and $\mathrm{Cl}$ was caused by the incorporation of carbonate and/or nitrate species. The carbonate anions were also responsible for the small band around $870 \mathrm{~cm}^{-1}$, due to the out-of-plane deformation mode of $\mathrm{CO}_{3}{ }^{2-}$ and $\mathrm{HCO}_{3}{ }^{-}$. This feature overlapped with the band around $850 \mathrm{~cm}^{-1}$, generated by the $\mathrm{OH}$ librational mode [46], which was better resolved in samples with small contributions of carbonates. At $650 \mathrm{~cm}^{-1}$ and below, the hydroxyl translational modes were observed. In the materials obtained in the presence of a starch template, a set of low-intensity bands associated with traces of the biopolymer residue were also visible.

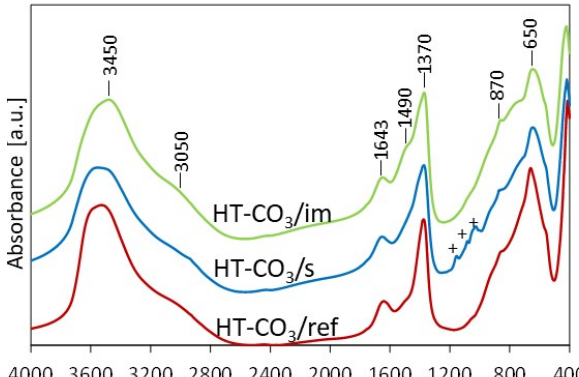

$400036003200 \quad 2800 \quad 2400 \quad 2000 \quad 1600$
Wavenumber $\left[\mathrm{cm}^{-1}\right]$

(a)

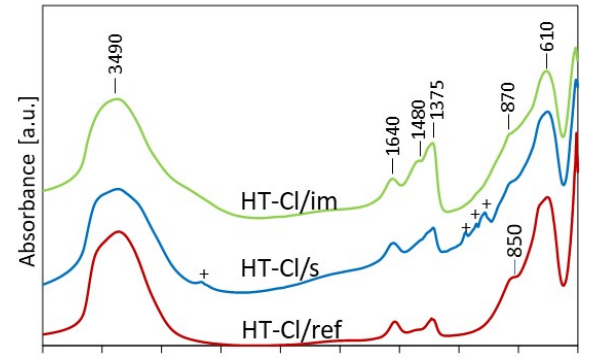

$40003600320028002400200016001200 \quad 800 \quad 400$ Wavenumber $\left[\mathrm{cm}^{-1}\right]$

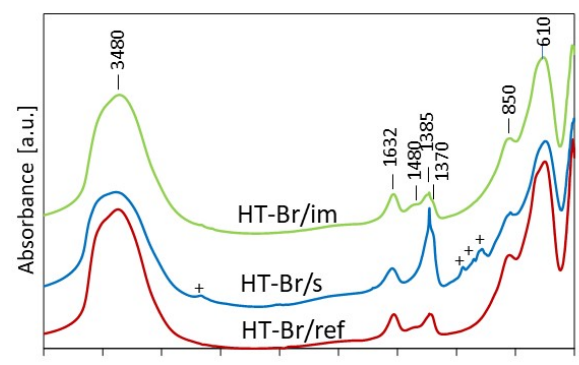

$40003600320028002400200016001200 \quad 800 \quad 400$ Wavenumber $\left[\mathrm{cm}^{-1}\right]$

(b)

(c)

Figure 3. FTIR spectra of the synthesized HT materials: (a) carbonate forms; (b) chloride forms; (c) bromide forms (+ bands originating from the remnants of starch).

The SEM analysis revealed that different synthesis procedures also affected the samples' morphology. This is illustrated in Figure 4, for chloride forms of HT. The HT-Cl/ref sample was composed of well-developed platelet particles, with a lateral size in the range of 100-200 nm (Figure 4c). In contrast, both the sample prepared by the inverse microemulsion method and the one synthesized in the presence of the starch template consisted of much finer grains. In the case of the $\mathrm{HT}-\mathrm{Cl} / \mathrm{im}$ sample, shapeless particles with dimensions of ca. 20-30 nm were observed (Figure 4a), while the $\mathrm{HT}-\mathrm{Cl} / \mathrm{s}$ material was composed of very tiny plates with diameters up to $50 \mathrm{~nm}$ (Figure $4 \mathrm{~b}$ ).

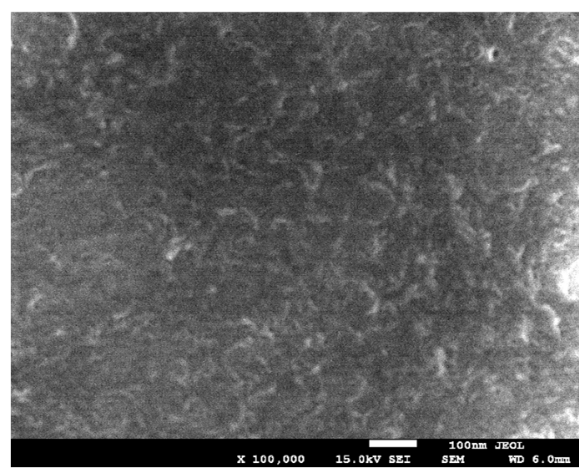

(a)

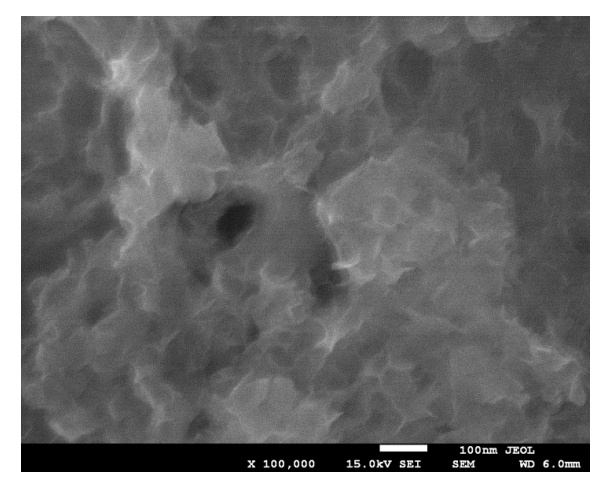

(b)

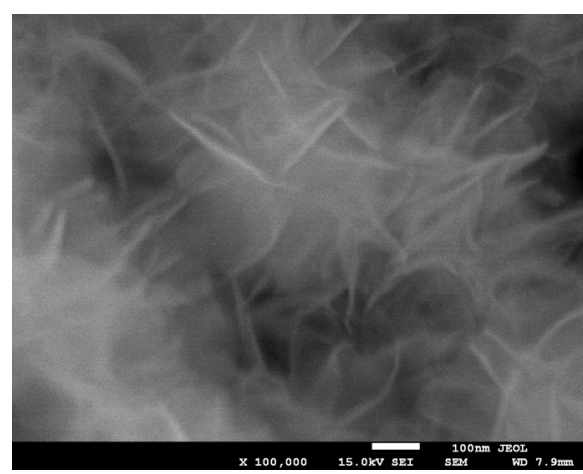

(c)

Figure 4. SEM micrographs of: (a) HT-Cl/im; (b) HT-Cl/s; (c) HT-Cl-ref. 


\subsection{Catalytic Testing}

The catalytic activity of the synthesized Mg-Al HT materials was tested in the liquid phase Baeyer-Villiger oxidation of cyclohexanone to $\varepsilon$-caprolactone. Hydrogen peroxide in combination with an acetonitrile solvent was used as an oxidant. The mechanism of the studied reaction is well-established [47-49]. Initially, Brønsted basic centers, i.e., hydroxyl groups at the HT catalyst surface, perform a nucleophilic activation of $\mathrm{H}_{2} \mathrm{O}_{2}$ by abstraction of a proton to form a hydroperoxide anion $\left(\mathrm{HOO}^{-}\right)$, which readily reacts with nitrile to yield peroxycarboximidic acid. The latter species performs a nucleophilic attack on the carbonyl group of the cyclohexanone molecule, forming an adduct referred to as a Criegee intermediate, which undergoes rearrangement to yield $\varepsilon$-caprolactone and acetamide (Figure 5).
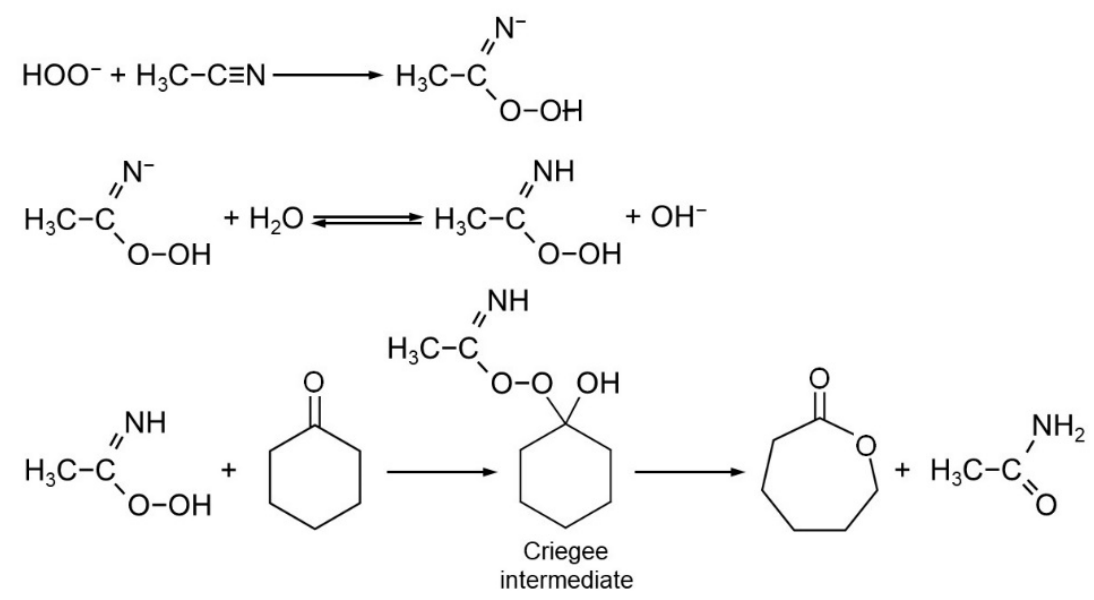

Figure 5. Reactions involved in the oxidation of cyclohexanone to $\varepsilon$-caprolactone with $\mathrm{H}_{2} \mathrm{O}_{2}$ /acetonitrile with the HT catalyst.

The catalytic experiments revealed that with all catalysts, $\varepsilon$-caprolactone was produced with high selectivity $(90-100 \%)$. The catalysts, after the reaction, retained the character of HT structures-as shown by the example of the HT- $\mathrm{Cl} /$ ref sample in Figure 2b. The activity of the catalysts differed strongly depending on the nature of interlayer anions in the HT catalysts, and on the degree of the HT materials' crystallinity. Figure 6 shows the yield of $\varepsilon$-caprolactone obtained for the studied materials.

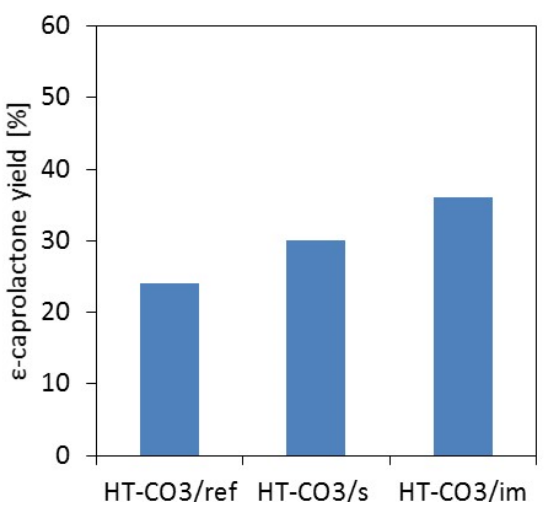

(a)

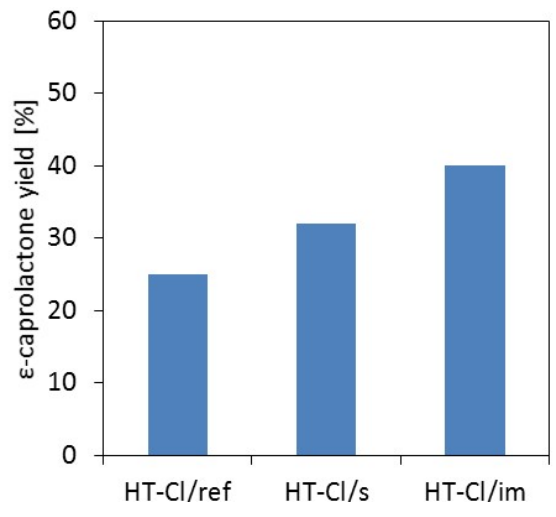

(b)

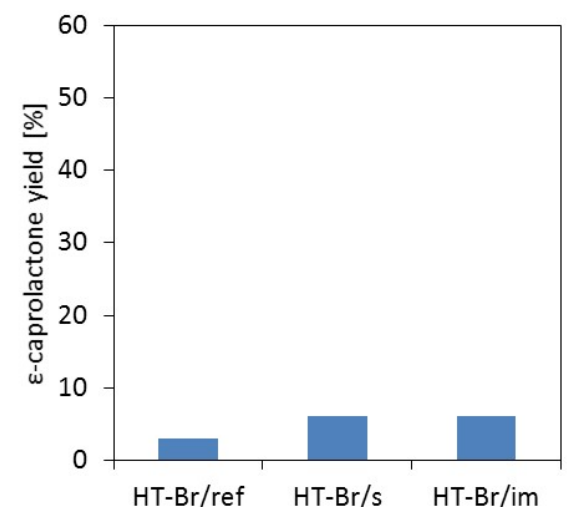

(c)

Figure 6. Yield of $\varepsilon$-caprolactone in HT materials: (a) carbonate forms; (b) chloride forms; (c) bromide forms.

It is evident that in the case of bromide forms of HT catalysts, a dramatic loss of activity was observed, irrespective of the method of catalyst preparation (Figure 6c). Analysis of the selectivity of $\mathrm{H}_{2} \mathrm{O}_{2}$ consumption showed that in the case of Br-containing catalysts it 
was about $5 \%$, while for the carbonate form of HT it was ca. $60 \%$. Thus, it appears that in the presence of $\mathrm{Br}$ forms of $\mathrm{HT}$, the decomposition of $\mathrm{H}_{2} \mathrm{O}_{2}$ tends to proceed via other pathways, induced by its contact with bromide anions [50], resulting, eventually, in a fall in catalytic performance. In view of this, the recommended cationic surfactant for the synthesis of HT/im catalysts should be a chloride rather than a bromide salt. All carbonate and chloride-based catalysts were active in the synthesis of $\varepsilon$-caprolactone (Figure $6 a, b)$. In accordance with previous findings [31,32], the yield of lactone grew with decreases in the crystal size of the HT catalyst - both for the carbonate and the chloride HT forms-making the catalysts prepared in the inverse micellar system the most productive ones ( $36 \%$ and $40 \%$ caprolactone yield for $\mathrm{HT}-\mathrm{CO}_{3} / \mathrm{im}$ and $\mathrm{HT}-\mathrm{Cl} / \mathrm{im}$, respectively).

However, it should be remembered that in weakly acidic conditions, such as those generated by the presence of $30 \% \mathrm{H}_{2} \mathrm{O}_{2}$ solution ( $\mathrm{pH}$ of the reaction medium around 5), leaching of magnesium and partial dissolution of the catalyst occur, leading to a loss of activity upon recycling [30]. To check on this aspect, experiments attempting the reuse of the selected catalysts obtained in the present work were conducted (Figure 7).

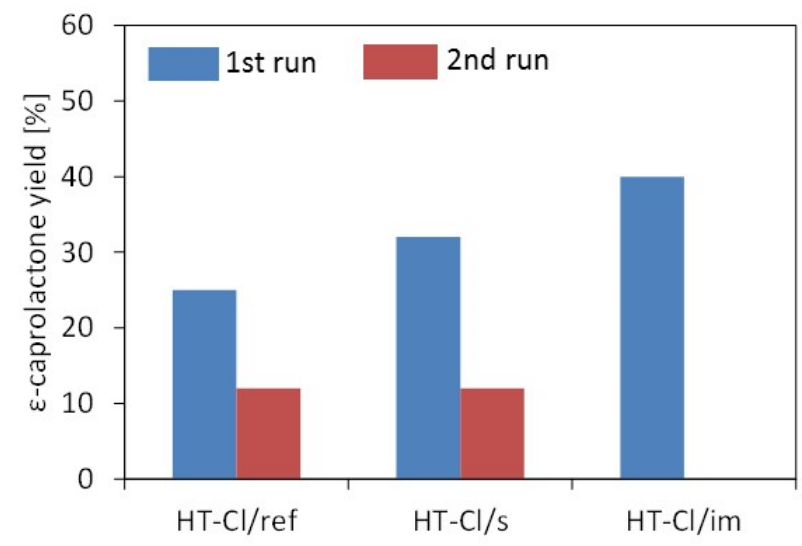

Figure 7. Recycling experiments using the chloride forms of the HT catalysts.

It is apparent that the deactivation of the catalysts did occur, and was especially pronounced in the case of the fine crystalline samples, in which the leaching/dissolution was most intense, due to the high surface-to-bulk ratio of the crystallites. Thus, in the case of the reference chloride HT catalyst, the yield of $\varepsilon$-caprolactone in the second run was about half of that obtained in the first run. Upon recycling of the catalyst prepared in the presence of starch, less than $40 \%$ of the first run yield was achieved. In the case of the most active catalyst, obtained by the inverse microemulsion method, it was impossible to recycle the catalyst after the first run, because its particles became so fine that they did not settle upon centrifugation and could not be recovered.

It has been shown that in the case of HT catalysts prepared by the conventional coprecipitation, the deactivation process can be prevented by alkalization of the reaction medium with sodium bicarbonate, which results in stabilization of the HT structure [51]. Besides increasing the $\mathrm{pH}$ of the reaction mixture, the addition of $\mathrm{NaHCO}_{3}$ opens up another way to activate $\mathrm{H}_{2} \mathrm{O}_{2}$, in which hydrogen peroxide reacts with bicarbonate to form peroxymonocarbonate $\left(\mathrm{HCO}_{4}{ }^{-}\right)$[52], an oxidizing species that acts in parallel to peroxycarboximidic anions. As a result, along with the enhanced HT catalyst stability, a substantial increase of the overall $\varepsilon$-caprolactone yield has been observed [51]. In view of this, the catalysts synthesized in the present work were subjected to the Baeyer-Villiger oxidation of cyclohexanone in the combined $\mathrm{H}_{2} \mathrm{O}_{2} /$ nitrile/bicarbonate system.

The results of the experiments with $\mathrm{NaHCO}_{3}$ addition are presented in Figure 8 . For all investigated catalysts, the yield of $\varepsilon$-caprolactone exceeded that observed in the system without bicarbonate, reaching the highest values with the catalysts prepared by starch templating and by the inverse microemulsion method (48-51\%). Additionally, with 
bromide forms of HT, the yield of $\varepsilon$-caprolactone was better than that obtained without $\mathrm{NaHCO}_{3}$ addition— but it did not exceed $10 \%$, and the series remained poorly active.

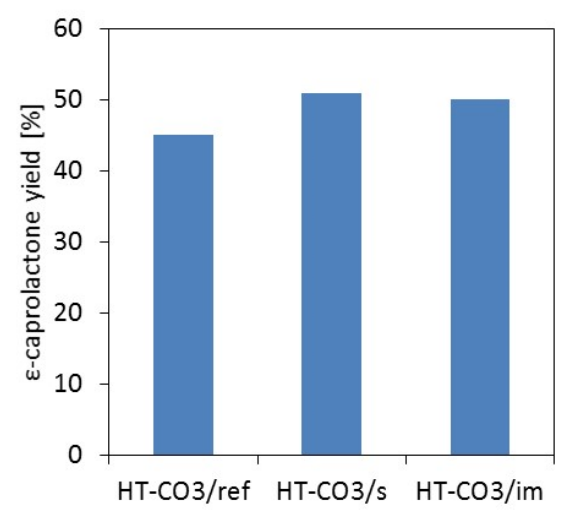

(a)

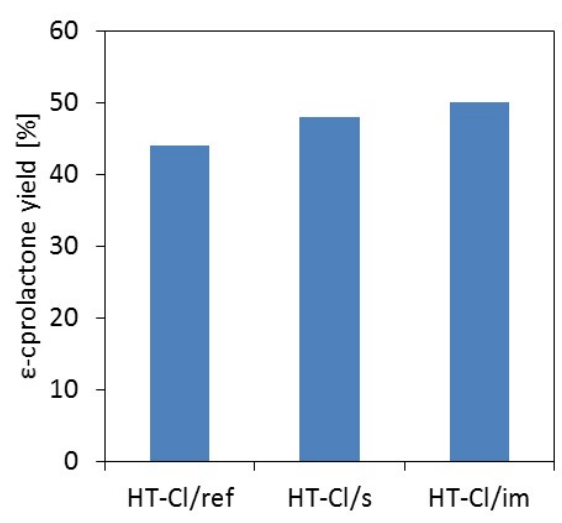

(b)

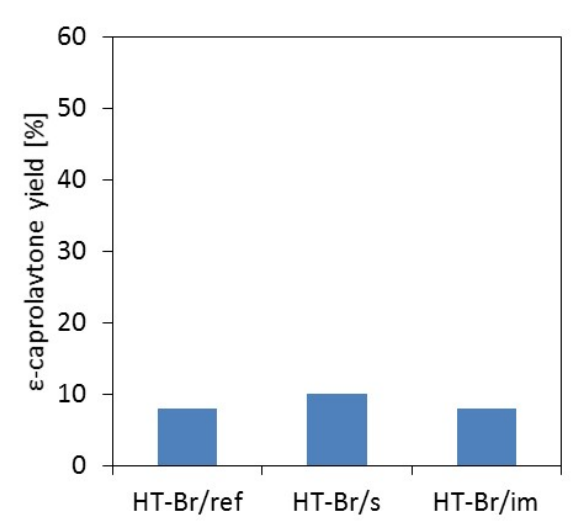

(c)

Figure 8. Yield of $\varepsilon$-caprolactone in HT materials in reaction medium alkalized with $\mathrm{NaHCO}_{3}$ : (a) carbonate forms; (b) chloride forms; (c) bromide forms.

However, most interesting was the impact of the modified reaction conditions on the catalysts' stability and the possibility of recycling them. Figure 9 shows the results of the catalyst reuse experiments. It is evident that the chloride forms of HT-which, when recycled without bicarbonate showed clear effects of deactivation progressing with the diminution of the catalyst crystallinity (Figure 7) - in the presence of $\mathrm{NaHCO}_{3}$ maintained high efficiency of $\varepsilon$-caprolactone production, irrespective of the method of synthesis. Moreover, the recycling experiment carried out with the HT-Br/s sample showed that the catalyst, poorly active in the first run, upon reuse displayed a spectacular improvement in catalytic performance and achieved a $\varepsilon$-caprolactone yield comparable to that of other samples. When looking for the cause of the latter effect, it should be recalled that HT materials possess high affinity to carbonate anions. Therefore, it is expected that during operation of the catalyst in the reaction mixture containing $\mathrm{HCO}_{3}{ }^{-} / \mathrm{CO}_{3}{ }^{2-}$ anions provided by bicarbonate, the interlayer chloride and bromide anions will be exchanged with the available carbonates. As a result, the composition of the catalysts, and, in consequence, their catalytic performance, become similar. Indeed, the EDS analysis of $\mathrm{Cl}$ and $\mathrm{Br}$ content in the selected catalysts after reaction with bicarbonate addition showed a major loss of halide anions from the structure (Table 1).

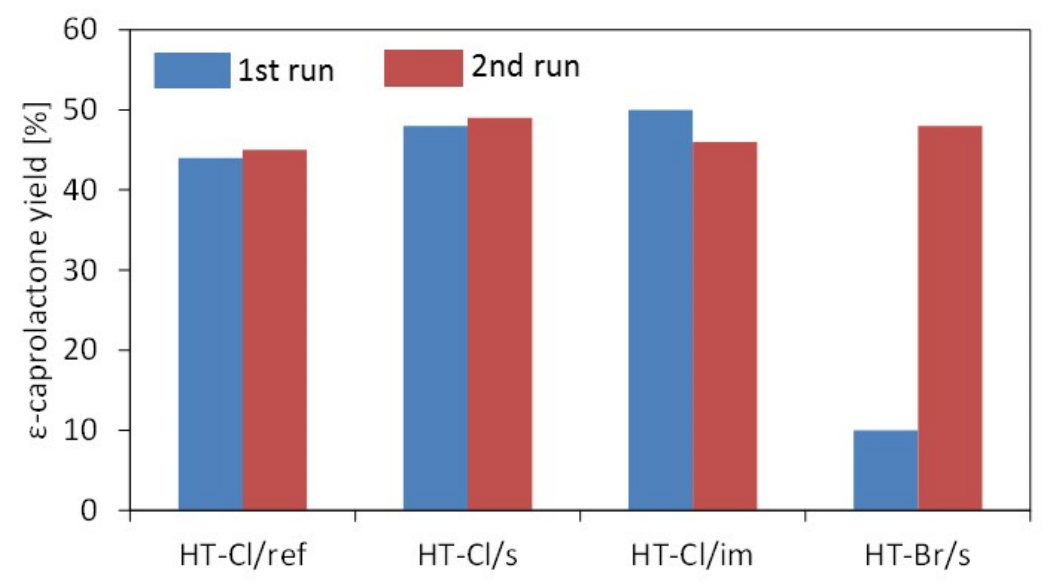

Figure 9. Recycling experiments over chloride forms of $\mathrm{HT}$ catalysts in the presence of $\mathrm{NaHCO}_{3}$. 
Replacement of interlayer halides with carbonates is further confirmed by comparison of FTIR spectra of $\mathrm{HT}-\mathrm{CO}_{3} / \mathrm{s}, \mathrm{HT}-\mathrm{Cl} / \mathrm{s}$ and $\mathrm{HT}-\mathrm{Br} / \mathrm{s}$ catalysts before and after reaction in the bicarbonate-containing reaction medium (Figure 10).

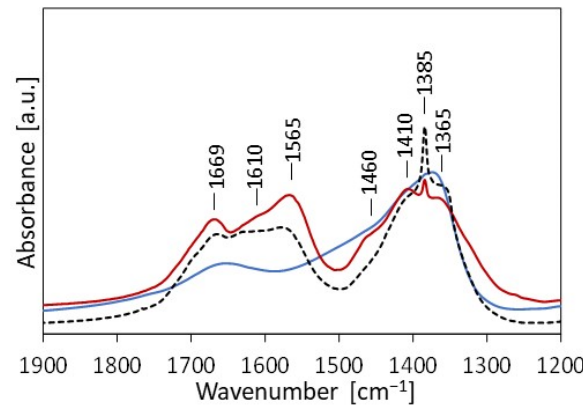

(a)

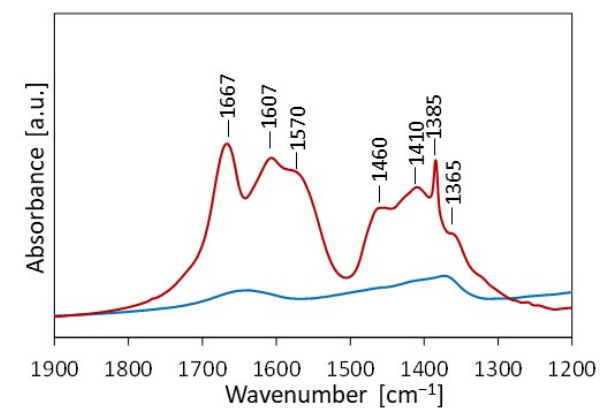

(b)

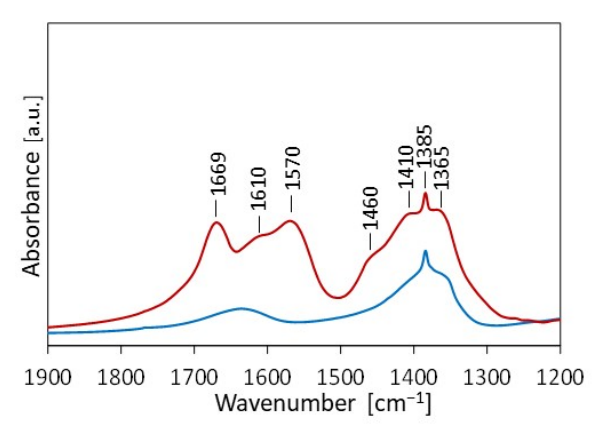

(c)

Figure 10. FTIR spectra of fresh (blue line) and spent (red line) HT catalysts: (a) HT- $\mathrm{CO}_{3} / \mathrm{s}$; (b) $\mathrm{HT}-\mathrm{Cl} / \mathrm{s}$; (c) $\mathrm{HT}-\mathrm{Br} / \mathrm{s}$. Dashed line-spectrum of $\mathrm{HT}-\mathrm{CO}_{3} / \mathrm{s}$ after reaction in acetonitrile $/ \mathrm{H}_{2} \mathrm{O}_{2}$ solution.

In the $1200-1900 \mathrm{~cm}^{-1}$ range, the spectra of fresh catalysts showed the already described differences, consisting primarily of different intensities of the complex, asymmetric bands characteristic of $\mathrm{HCO}_{3}{ }^{-} / \mathrm{CO}_{3}{ }^{2-}$ species, with a maximum around $1370-1375 \mathrm{~cm}^{-1}$. While in $\mathrm{HT}-\mathrm{CO}_{3} / \mathrm{s}$ these absorptions were very strong, in $\mathrm{HT}-\mathrm{Cl} / \mathrm{s}$ and $\mathrm{HT}-\mathrm{Br} / \mathrm{s}$, where carbonates (and, in the case of HT-Br/s, nitrates) appeared as contaminants, the band was much less intense. After the reaction, in $\mathrm{HT}-\mathrm{Cl} / \mathrm{s}$ and $\mathrm{HT}-\mathrm{Br} / \mathrm{s}$, a buildup of spectrum intensity was observed in the area where the $\mathrm{HCO}_{3}{ }^{-} / \mathrm{CO}_{3}{ }^{2-}$ modes appeared, indicating that the eliminated halides had been substituted by carbonates. In addition, in all the spectra, a set of bands at ca. 1670, 1610, 1570, 1460, 1410, 1385, $1365 \mathrm{~cm}^{-1}$ overlapped with the carbonate/bicarbonate absorptions, so that the overall FTIR characteristics became similar for all the spent catalysts. Most of the new bands may be attributed to the adsorbed acetamide/acetamide anion species [53-56]. Acetamide may be formed in this system not only as a byproduct of cyclohexanone oxidation with peroxycarboximidic acid (Figure 5), but also as a result of the reaction of peroxycarboximidic acid with $\mathrm{H}_{2} \mathrm{O}_{2}$ [48] or as a product of acetonitrile interaction with hydroxyls at the surface of a HT catalyst [56] (Figure 11). Thus, the band at $1670 \mathrm{~cm}^{-1}$ was due to the stretching of the carbonyl group, those at 1610 and $1570 \mathrm{~cm}^{-1}$ fell in the range of NH bending modes, and the bands at 1460 , 1410 and $1365 \mathrm{~cm}^{-1}$ may be attributed to $\mathrm{CH}_{3}$ deformation vibrations. The $1410 \mathrm{~cm}^{-1}$ band also encompassed a contribution from the $\mathrm{C}-\mathrm{N}$ stretching mode.
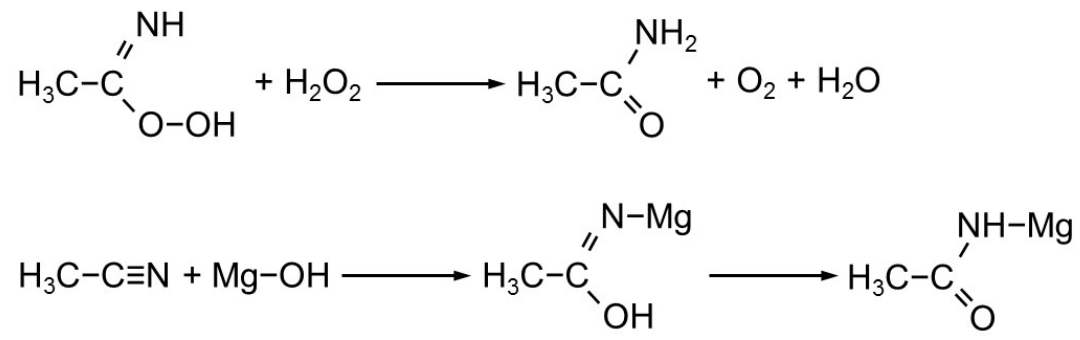

Figure 11. Paths of an acetamide-like species formation alternative to the Baeyer-Villiger reaction.

Noteworthily, apart from the acetamide, the spectra of the spent catalysts bore no discernible presence of adsorbed forms of other stable reagents present in the reaction medium, e.g., cyclohehexanone, $\varepsilon$-caprolactone or acetonitrile. This may be taken as an indication that the main source of the acetamide-related bands was the reaction of acetonitrile with surface hydroxyls, resulting in strongly chemisorbed species, as described by Lavalley [56] (Figure 11). This supposition is further supported by the fact that a 
similar spectrum arose for the catalyst treated with the reaction mixture containing only acetonitrile and $\mathrm{H}_{2} \mathrm{O}_{2}$ (Figure $10 \mathrm{a}$ dashed line). After the reaction, with all catalysts, a band at $1385 \mathrm{~cm}^{-1}$ - characteristic of a $\mathrm{NO}_{3}{ }^{-}$anion-became visible. Its appearance indicates that upon contact with $\mathrm{H}_{2} \mathrm{O}_{2}$, part of the acetamide species undergoes complete mineralization to nitrates-in accordance with the study of Leitner et al. [57].

In general, in the reaction system with $\mathrm{NaHCO}_{3}$ addition, the differences in activity between the fine crystalline catalysts obtained by different methods all but vanished, although for the chloride and carbonate forms, both the HT/im and the HT/s samples performed systematically better than the references. In view of the similarity in the catalytic performance of the finely crystalline HT materials in the system using bicarbonate, for practical applications, the synthesis method based on the use of a starch template-due to its technical simplicity and low cost-appears to be the procedure of choice.

\section{Experimental Section}

\subsection{Materials}

The inverse microemulsion method used for the synthesis of $\mathrm{Mg}-\mathrm{Al}$ (3:1) HT materials followed previously published procedures [35,37]. In the first step, inverse microemulsions of hydrotalcite-forming reagents were prepared. One emulsion contained an aqueous solution of $\mathrm{Mg}\left(\mathrm{NO}_{3}\right)_{2}$ (concentration $0.375 \mathrm{M}$ ) and $\mathrm{Al}\left(\mathrm{NO}_{3}\right)_{3}$ (concentration $0.125 \mathrm{M}$ ); in the other, the precipitating agent $\left(\mathrm{NH}_{3} \mathrm{aq}\right.$, concentration $3 \mathrm{M}$ ) was dissolved. Each of these solutions was dispersed in an organic medium based on isooctane as an oil phase, cetyltrimethylammonium bromide $(\mathrm{CTABr})$ or cetyltrimethylammonium chloride $(\mathrm{CTACl})$ as a surfactant, and n-butanol as a co-surfactant. For each microemulsion, the applied proportions were: $3.4 \mathrm{~mL}$ aqueous phase/3.12 g surfactant/4.81 g co-surfactant/6.21 g oil phase. Equal volumes of the two microemulsions were mixed and aged at $70{ }^{\circ} \mathrm{C}$ for $16 \mathrm{~h}$ to enable precipitation of the hydrotalcite-like phase, referred to as $\mathrm{HT}-\mathrm{Br} / \mathrm{im}$ or $\mathrm{HT}-\mathrm{Cl} / \mathrm{im}$. The solid product was separated by centrifugation, washed three times using a 1:1 water $/ \mathrm{EtOH}$ mixture, and freeze-dried. In addition, $\mathrm{HT}-\mathrm{CO}_{3} / \mathrm{im}$ was prepared by subjecting $\mathrm{HT}-\mathrm{Cl} / \mathrm{im}$ to anion exchange with ammonium carbonate solution, followed by washing and freeze drying.

Starch-modified HT materials were prepared by co-precipitation at constant $\mathrm{pH}=10$, with all reagents dissolved in the gelatinized aqueous solution of starch prepared by heating of $0.2 \mathrm{wt}$ \% starch suspension in water at $95^{\circ} \mathrm{C}$ for $3 \mathrm{~h}$ [39]. The syntheses were performed at room temperature. Solutions of $\mathrm{Mg}\left(\mathrm{NO}_{3}\right)_{2}$ and $\mathrm{Al}\left(\mathrm{NO}_{3}\right)_{3}$ (concentrations 0.75 and $0.25 \mathrm{M}$, respectively), and $10 \% \mathrm{NH}_{3}$ aq as a precipitating agent, were used. Depending on the preferred interlayer anion, the precipitation was carried out in a solution of ammonium carbonate, chloride, or bromide, in double excess with respect to the stoichiometric demand. The materials were washed with cold water and freeze-dried. The samples prepared with this method are referred as $\mathrm{HT}-\mathrm{CO}_{3} / \mathrm{s}, \mathrm{HT}-\mathrm{Br} / \mathrm{s}$, and $\mathrm{HT}-\mathrm{Cl} / \mathrm{s}$.

Reference HT samples were prepared from a common precursor, i.e., the nitrate form of $\mathrm{Mg}-\mathrm{Al}$ (3:1) HT, obtained by the standard co-precipitation method at constant $\mathrm{pH}=10$, using $10 \% \mathrm{NH}_{3}$ aq as the precipitating agent [58]. The $\mathrm{HT}-\mathrm{NO}_{3}$ precipitate was subjected to anion exchange with aqueous solutions of $\mathrm{Na}_{2} \mathrm{CO}_{3}, \mathrm{NaCl}$, or $\mathrm{NaBr}$ to yield, after washing with water and drying in a drying box, the solids referred to as $\mathrm{HT}-\mathrm{CO}_{3} /$ ref, $\mathrm{HT}-\mathrm{Br} / \mathrm{ref}$, $\mathrm{HT}-\mathrm{Cl} /$ ref.

All chemicals used for synthesis were p.a. purity, purchased from Avantor Performance Materials SA (Gliwice, Poland) and used as received. Commercial potato starch was manufactured by PPZ Trzemeszno (Trzemeszno, Poland).

\subsection{Methods}

X-ray diffraction (XRD) patterns were recorded with an X'Pert PRO MPD (PANalytical, Almelo, The Netherlands) diffractometer, using $\mathrm{Cu} \mathrm{K} \alpha$ radiation $(40 \mathrm{kV}, 30 \mathrm{~mA})$, a flat graphite monochromator in the diffracted beam, and a step size of $0.0334^{\circ}$. Crystal sizes (the sizes of coherently scattering domains) of the HT materials in the c and a direction 
of the unit cell, corresponding to the plate-like crystal thickness and lateral dimension, were estimated by analyzing the broadening of (003) and (110) reflections with the Scherrer equation, using X'Pert High Score software (version 3.0, PANalytical, Almelo, The Netherlands).

Scanning electron microscopy-energy dispersive X-ray spectroscopy (SEM/EDS) analysis was carried out with the aid of JEOL JSM-7500F (JEOL, Tokyo, Japan), coupled with an AZtecLiveLite Xplore 30 (Oxford Instruments, Abingdon, UK) system. SEM images were recorded for the uncoated samples deposited on 200 mesh copper grids covered with a carbon support film.

Fourier transform infrared (FT-IR) spectra were recorded in transmission mode using a Nicolet 6700 (Thermo Scientific, Madison, WI, USA) spectrometer under atmospheric conditions. Spectra of the samples were recorded as KBr discs in the range of $4000-400 \mathrm{~cm}^{-1}$ at a spectral resolution of $2 \mathrm{~cm}^{-1}$.

Catalytic tests of Baeyer-Villiger oxidation of cyclohexanone were carried out for $3 \mathrm{~h}$ at $70{ }^{\circ} \mathrm{C}$ in a glass reactor nested in a magnetic stirrer equipped with a heat-on system in the presence of $0.125 \mathrm{~g}$ of catalyst. The reaction mixture consisted of $12.5 \mathrm{mmol}$ of cyclohexanone, $100 \mathrm{mmol}$ of $30 \%$ hydrogen peroxide solution and $200 \mathrm{mmol}$ of acetonitrile $(\mathrm{ACN})$. For all catalysts, reactions with the addition of sodium bicarbonate were also performed [36]. Four $\times 0.03 \mathrm{~g}$ of $\mathrm{NaHCO}_{3}$ was added to the reaction mixture after 1 , 15,30 and $120 \mathrm{~min}$ of reaction duration. In experiments with catalyst reuse, the total volume of the reaction mixture was centrifuged, the liquid phase removed, and the catalyst transferred into a reaction vessel with a new portion of the reagents. The reaction mixtures were analyzed by gas chromatography using a Thermo Trace GC Ultra instrument (Thermo Electron Corporation, Austin, TX, USA) fitted with a TR- 5 capillary column and with a flame ionization detector. Conversion of cyclohexanone was measured as the percentage of substrate consumed during the reaction. Selectivity to $\varepsilon$-caprolactone was determined as the ratio of the molar quantity of product produced to the molar quantity of converted cyclohexanone, multiplied by 100. Conversion and selectivity data were established as an arithmetic average from 3 experiments for each catalyst. Selected reaction mixtures were subjected to GC-MS analysis using a Thermo Trace GC Ultra instrument (Thermo Electron Corporation, Austin, TX, USA) fitted with a TR-5-MS capillary column and a DSQ II quadrupole mass detector. All reagents and solvents used for catalytic tests were purchased from Merck (Darmstadt, Germany) and used as received.

\section{Conclusions}

Both the inverse microemulsion method and the starch-templated co-precipitation proved efficient in the preparation of fine crystalline $\mathrm{Mg}$-Al HT solids. The order of crystallinity was HT/ref $>\mathrm{HT} / \mathrm{s}>\mathrm{HT} / \mathrm{im}$. The obtained materials were active in the liquid phase oxidation of cyclohexanone with the hydrogen peroxide/nitrile systemthe activity strongly depending on the nature of the interlayer anions. In particular, the presence of bromides was harmful for the catalytic performance, as it induced nonselective consumption of $\mathrm{H}_{2} \mathrm{O}_{2}$.

The yield of $\varepsilon$-caprolactone increased with the decreasing crystal size of the HT materials, the HT/im catalysts of finest crystallinity being the most active ones. In contrast, the catalysts' stability decreased with the loss of crystallinity, adversely affecting the efficiency of the catalyst reuse.

In reactions performed with the addition of $\mathrm{NaHCO}_{3}$, all catalysts produced more $\varepsilon$ caprolactone than without bicarbonate, and maintained high activity upon recycling, with halide forms of HT undergoing transformation into carbonate ones. The fine crystalline catalysts performed better than the references, but between themselves showed comparable activity and resilience, irrespective of the method of preparation. Therefore, for practical applications, synthesis based on a simple and cheap starch templating approach appears particularly attractive. 
Author Contributions: Conceptualization, R.K. and E.M.S.; investigation, R.K., B.D.N., A.M., J.K.-C. and D.D.; writing—original draft preparation, R.K.; writing—review and editing, E.M.S., R.K. and J.K.-C.; supervision, E.M.S.; funding acquisition, E.M.S. All authors have read and agreed to the published version of the manuscript.

Funding: This research was funded by the Polish National Science Center (NCN), grant OPUS, UMO-2017/27/B/ST5/01834.

Data Availability Statement: The data presented in this study are available on request from the corresponding author.

Conflicts of Interest: The authors declare no conflict of interest. The funders had no role in the design of the study; in the collection, analyses, or interpretation of data; in the writing of the manuscript, or in the decision to publish the results.

\section{References}

1. Zhitova, E.S.; Krivovichev, S.V.; Pekov, I.V.; Greenwell, H.C. Crystal chemistry of natural layered double hydroxides. 5. Singlecrystal structure refinement of hydrotalcite, $\left[\mathrm{Mg}_{6} \mathrm{Al}_{2}(\mathrm{OH})_{16}\right]\left(\mathrm{CO}_{3}\right)\left(\mathrm{H}_{2} \mathrm{O}\right)_{4}$. Miner. Mag. 2019, 83, 269-280. [CrossRef]

2. Cavani, F.; Trifirò, F.; Vaccari, A. Hydrotalcite-type anionic clays: Preparation, properties and applications. Cat. Today 1991, 11, 173-301. [CrossRef]

3. Centi, G.; Perathoner, S. Catalysis by layered materials: A review. Micropor. Mesopor. Mater. 2008, 107, 3-15. [CrossRef]

4. Othman, M.R.; Helwani, Z.; Martunus Fernando, W.J.N. Synthetic hydrotalcites from different routes and their application as catalysts and gas adsorbents: A review. Appl. Organomet. Chem. 2009, 23, 335-346. [CrossRef]

5. Roelofs, J.C.A.A.; Lensveld, D.J.; van Dillen, A.J.; de Jong, K.P. On the Structure of Activated Hydrotalcites as Solid Base Catalysts for Liquid-Phase Aldol Condensation. J. Catal. 2001, 203, 184-191. [CrossRef]

6. Climent, M.; Corma, A.; Iborra, S.; Epping, K.; Velty, A. Increasing the basicity and catalytic activity of hydrotalcites by different synthesis procedures. J. Catal. 2004, 225, 316-326. [CrossRef]

7. Abelló, S.; Medina, F.; Tichit, D.; Pérez-Ramírez, J.; Groen, J.C.; Sueiras, J.E.; Salagre, P.; Cesteros, Y. Aldol Condensations Over Reconstructed Mg-Al Hydrotalcites: Structure-Activity Relationships Related to the Rehydration Method. Chem. Eur. J. 2004, 11, 728-739. [CrossRef]

8. Winter, F.; van Dillen, A.J.; de Jong, K.P. Supported hydrotalcites as highly active solid base catalysts. Chem. Commun. 2005, 3977-3979. [CrossRef]

9. Kuśtrowski, P.; Sułkowska, D.; Chmielarz, L.; Dziembaj, R. Aldol condensation of citral and acetone over mesoporous catalysts obtained by thermal and chemical activation of magnesium-aluminum hydrotalcite-like precursors. Appl. Catal. A Gen. 2006, 302, 317-324. [CrossRef]

10. Helwani, Z.; Othman, M.R.; Aziz, N.; Kim, J.; Fernando, W.J.N. Solid heterogeneous catalysts for transesterification of triglycerides with methanol: A review. Appl. Catal. A Gen. 2009, 363, 1-10. [CrossRef]

11. Jothiramalingam, R.; Wang, M.K. Review of Recent Developments in Solid Acid, Base, and Enzyme Catalysts (Heterogeneous) for Biodiesel Production via Transesterification. Ind. Eng. Chem. Res. 2009, 48, 6162-6172. [CrossRef]

12. Debecker, D.P.; Gaigneaux, E.M.; Busca, G. Exploring, Tuning, and Exploiting the Basicity of Hydrotalcites for Applications in Heterogeneous Catalysis. Chem. Eur. J. 2009, 15, 3920-3935. [CrossRef]

13. Lee, G.; Jeong, Y.; Takagaki, A.; Jung, J.C. Sonication assisted rehydration of hydrotalcite catalyst for isomerization of glucose to fructose. J. Mol. Catal. A-Chem. 2014, 393, 289-295. [CrossRef]

14. Delidovich, I.; Palkovits, R. Structure-performance correlations of Mg-Al hydrotalcite catalysts for the isomerization of glucose into fructose. J. Catal. 2015, 327, 1-9. [CrossRef]

15. Kikhtyanin, O.; Hora, L.; Kubička, D. Unprecedented selectivities in aldol condensation over Mg-Al hydrotalcite in a fixed bed reactor setup. Catal. Commun. 2015, 58, 89-92. [CrossRef]

16. Wang, Y.T.; Fang, Z.; Zhang, F.; Xue, B.J. One-step production of biodiesel from oils with high acid value by activated Mg-Al hydrotalcite nanoparticles. Bioresour. Technol. 2015, 193, 84-89. [CrossRef]

17. Landeros, J.M.; Juaristi, E. Mechanochemical Synthesis of Dipeptides Using Mg-Al Hydrotalcite as Activating Agent under Solvent-Free Reaction Conditions. Eur. J. Org. Chem. 2017, 2017, 687-694. [CrossRef]

18. Hincapié, G.; López, D.; Moreno, A. Infrared analysis of methanol adsorption on mixed oxides derived from $\mathrm{Mg} / \mathrm{Al}$ hydrotalcite catalysts for transesterification reactions. Catal. Today 2018, 302, 277-285. [CrossRef]

19. Wang, H.; Liu, W.; Wang, Y.; Tao, N.; Cai, H.; Liu, J.; Lv, J. Mg-Al Mixed Oxide Derived from Hydrotalcites Prepared by Solvent-free Method: A Stable Acid-base Bifunctional Catalyst for Continuous-Flow Transesterification of Dimethyl carbonate and Ethanol. Ind. Eng. Chem. Res. 2020, 59, 5591-5600. [CrossRef]

20. Hussain, S.; Velisoju, V.K.; Rajan, N.P.; Kumar, B.P.; Chary, K.V.R. Synthesis of $\gamma$-Valerolactone from Levulinic Acid and Formic Acid over Mg-Al Hydrotalcite Like Compound. Chem. Sel. 2018, 3, 6186-6194. [CrossRef]

21. Yabushita, M.; Shibayama, N.; Nakajima, K.; Fukuoka, A. Selective Glucose-to-Fructose Isomerization in Ethanol Catalyzed by Hydrotalcites. ACS Catal. 2019, 3, 2101-2109. [CrossRef] 
22. An, S.; Kwon, D.; Cho, J.; Jung, J.C. Effect of the Solvent on the Basic Properties of Mg-Al Hydrotalcite Catalysts for Glucose Isomerization. Catalysts 2020, 10, 1236. [CrossRef]

23. Kaneda, K.; Ueno, S. Development of Hydrotalcite Catalysts in Heterogeneous Baeyer-Villiger Oxidation. ACS Symp. Ser. 1996, 638, 300-318.

24. Pillai, U. Sn-exchanged hydrotalcites as catalysts for clean and selective Baeyer-Villiger oxidation of ketones using hydrogen peroxide. J. Mol. Catal. A-Chem. 2003, 191, 93-100. [CrossRef]

25. Kawabata, T.; Fujisaki, N.; Shishido, T.; Nomura, K.; Sano, T.; Takehira, K. Improved Fe/Mg-Al hydrotalcite catalyst for Baeyer-Villiger oxidation of ketones with molecular oxygen and benzaldehyde. J. Mol. Catal. A-Chem. 2006, 253, 279-289. [CrossRef]

26. Llamas, R.; Jiménez-Sanchidrián, C.; Ruiz, J.R. Heterogeneous Baeyer-Villiger oxidation of ketones with $\mathrm{H}_{2} \mathrm{O}_{2} /$ nitrile, using $\mathrm{Mg} / \mathrm{Al}$ hydrotalcite as catalyst. Tetrahedron 2007, 63, 1435-1439. [CrossRef]

27. Jiménez-Sanchidrián, C.; Ruiz, J.R. The Baeyer-Villiger reaction on heterogeneous catalysts. Tetrahedron 2008, 64, 2011-2026. [CrossRef]

28. Chen, C.; Peng, J.; Li, B.; Wang, L. The Catalytic Baeyer-Villiger Oxidation of Cyclohexanone to $\varepsilon$-Caprolactone over Stibiumcontaining Hydrotalcite. Catal. Lett. 2009, 131, 618-623. [CrossRef]

29. Kaneda, K.; Mizugaki, T. Design of High-Performance Heterogeneous Catalysts Using Hydrotalcite for Selective Organic Transformations. Green Chem. 2019, 21, 1361-1389. [CrossRef]

30. Olszówka, J.; Karcz, R.; Napruszewska, B.D.; Duraczyńska, D.; Gaweł, A.; Bahranowski, K.; Serwicka, E.M. Baeyer-Villiger oxidation of cyclohexanone with $\mathrm{H}_{2} \mathrm{O}_{2}$ /acetonitrile over hydrotalcite-like catalysts: Effect of $\mathrm{Mg} / \mathrm{Al}$ ratio on the $\varepsilon$-caprolactone yield. Catal. Commun. 2017, 100, 196-201. [CrossRef]

31. Olszówka, J.E.; Karcz, R.; Napruszewska, B.D.; Michalik-Zym, A.; Duraczyńska, D.; Kryściak-Czerwenka, J.; Niecikowska, A.; Bahranowski, K.; Serwicka, E.M. Effect of Mg-Al hydrotalcite crystallinity on catalytic Baeyer-Villiger oxidation of cyclohexanone with $\mathrm{H}_{2} \mathrm{O}_{2}$ /acetonitrile. Catal. Commun. 2018, 107, 48-52. [CrossRef]

32. Olszówka, J.E.; Karcz, R.; Michalik-Zym, A.; Napruszewska, B.D.; Bielańska, E.; Kryściak-Czerwenka, J.; Socha, R.P.; Nattich-Rak, M.; Krzan, M.; Klimek, A.; et al. Effect of grinding on the physico-chemical properties of Mg-Al hydrotalcite and its performance as a catalyst for Baeyer-Villiger oxidation of cyclohexanone. Catal. Today 2019, 333, 147-153. [CrossRef]

33. Woodruff, M.A.; Hutmacher, D.W. The return of a forgotten polymer-Polycaprolactone in the 21st century. Progr. Polym. Sci. 2010, 35, 1217-1256. [CrossRef]

34. Suwantong, O. Biomedical applications of electrospun polycaprolactone fiber mats. Polym. Adv. Technol. 2016, 27, 1264-1273. [CrossRef]

35. Bellezza, F.; Cipiciani, A.; Costantino, U.; Nocchetti, M.; Posati, T. Hydrotalcite-Like Nanocrystals from Water-in-Oil Microemulsions. Eur. J. Inorg. Chem. 2009, 2603-2611. [CrossRef]

36. Holgado, P.H.; Holgado, M.J.; San Román, M.S.; Rives, V. Effect of surfactants on the properties of hydrotalcites prepared by the reverse micelle method. Mater. Chem. Phys. 2015, 151, 140-148. [CrossRef]

37. Napruszewska, B.D.; Michalik-Zym, A.; Dula, R.; Bielańska, E.; Rojek, W.; Machej, T.; Socha, R.P.; Lityńska-Dobrzyńska, L.; Bahranowski, K.; Serwicka, E.M. Composites derived from exfoliated Laponite and Mn-Al hydrotalcite prepared in inverse microemulsion: A new strategy for design of robust VOCs combustion catalysts. Appl. Catal. B-Environ. 2017, 211, 46-56. [CrossRef]

38. Napruszewska, B.D.; Michalik-Zym, A.; Dula, R.; Duraczyńska, D.; Rojek, W.; Socha, R.P.; Lityńska-Dobrzyńska, L.; Bahranowski, K.; Serwicka, E.M. VOCs combustion catalysts based on composites of exfoliated organo-Laponite and multimetallic (Mn, Al, Zr, Ce) hydrotalcites prepared by inverse microemulsion. Catal. Today 2019, 333, 183-189. [CrossRef]

39. Michalik, A.; Napruszewska, B.D.; Walczyk, A.; Kryściak-Czerwenka, J.; Duraczyńska, D.; Serwicka, E.M. Synthesis of Nanocrystalline Mg-Al Hydrotalcites in the Presence of Starch—the Effect on Structure and Composition. Materials 2020, 13, 602. [CrossRef]

40. Miyata, S. Anion-Exchange Properties of Hydrotalcite-Like Compounds. Clays Clay Miner. 1983, 31, 305-311. [CrossRef]

41. Solin, S.A.; Hines, D.; Yun, S.K.; Pinnavaia, T.J.; Thorpe, M.F. Layer rigidity in 2D disordered Ni-Al layer double hydroxides. J. Non-Cryst. Solids 1995, 182, 212-220. [CrossRef]

42. Roobottom, H.K.; Jenkins, H.D.B.; Passmore, J.; Glasser, L. Thermochemical Radii of Complex Ions. J. Chem. Educ. 1999, 76, 1570-1573. [CrossRef]

43. Olszówka, J.E.; Karcz, R.; Bielańska, E.; Kryściak-Czerwenka, J.; Napruszewska, B.D.; Sulikowski, B.; Socha, R.P.; Gaweł, A.; Bahranowski, K.; Olejniczak, Z.; et al. New insight into the preferred valency of interlayer anions in hydrotalcite-like compounds: The effect of $\mathrm{Mg}$ / Al ratio. Appl. Clay Sci. 2018, 155, 84-94. [CrossRef]

44. Kloprogge, J.T.; Frost, R.L. Infrared and Raman Spectroscopic Studies of Layered Double Hydroxides (LDHs). In Layered Double Hydroxides: Present and Future; Rives, V., Ed.; Nova Science Publishers: New York, NY, USA, 2001; Chapter 5; pp. 139-192.

45. López, T.; Bosch, P.; Asomoza, M.; Gómez, R.; Ramos, E. DTA-TGA and FTIR spectroscopies of sol-gel hydrotalcites: Aluminum source effect on physicochemical properties. Mater. Lett. 1997, 31, 311-316. [CrossRef]

46. Kagunya, W.; Baddour-Hadjean, R.; Kooli, F.; Jones, W. Vibrational modes in layered double hydroxides and their calcined derivatives. Chem. Phys. 1998, 236, 225-234. [CrossRef]

47. Payne, G.B.; Deming, P.H.; Williams, P.H. Reactions of hydrogen peroxide. VII. Alkali-catalyzed Epoxidation and oxidation using a nitrile as co-reactant. J. Organomet. Chem. 1961, 26, 659-663. [CrossRef] 
48. Prihod'ko, R.; Sychev, M.; Kolomitsyn, I.; Stobbelaar, P.J.; Hensen, E.J.M.; van Santen, R.A. Layered double hydroxides as catalysts for aromatic nitrile hydrolysis. Micropor. Mesopor. Mat. 2002, 56, 241-255. [CrossRef]

49. Jiménez-Sanchidrián, C.; Hidalgo, J.M.; Llamas, R.; Ruiz, J.R. Baeyer-Villiger oxidation of cyclohexanone with hydrogen peroxide/benzonitrile over hydrotalcites as catalysts. Appl. Catal. A-Gen. 2006, 312, 86-94. [CrossRef]

50. Bray, W.C.; Livingston, R.S. The catalytic decomposition of hydrogen peroxide in a bromine-bromide solution, and a study of the steady state. J. Am. Chem. Soc. 1923, 45, 1251-1271. [CrossRef]

51. Karcz, R.; Olszówka, J.E.; Napruszewska, B.D.; Kryściak-Czerwenka, J.; Serwicka, E.M.; Klimek, A.; Bahranowski, K. Combined $\mathrm{H}_{2} \mathrm{O}_{2} /$ nitrile/bicarbonate system for catalytic Baeyer-Villiger oxidation of cyclohexanone to $\varepsilon$-caprolactone over $\mathrm{Mg} \mathrm{Al}$ hydrotalcite catalysts. Catal. Commun. 2019, 132, 105821. [CrossRef]

52. Richardson, D.E.; Yao, H.; Frank, K.M.; Bennett, D.A. Equilibria, kinetics, and mechanism in the bicarbonate activation of hydrogen peroxide: Oxidation of sulfides by peroxymonocarbonate. J. Am. Chem. Soc. 2000, 122, 1729-1739. [CrossRef]

53. Uno, T.; Machida, K.; Saito, Y. Out-of-plane vibrations of acetamide and partially N-deuterated acetamide. Spectrochim. Acta A-Mol. Spectrosc. 1971, 27, 833-844. [CrossRef]

54. Koubowetz, F.; Latzel, J.; Noller, H. Adsorption of acetonitrile on magnesia, an IR and TPD study. J. Coll. Interface Sci. 1980, 74, 322-330. [CrossRef]

55. Larrubia, M.A.; Ramis, G.; Busca, G. An FT-IR study of the adsorption and oxidation of N-containing compounds over $\mathrm{Fe}_{2} \mathrm{O}_{3}$-TiO $\mathrm{T}_{2}$ SCR catalysts. Appl. Catal. B-Environ. 2001, 30, 101-110. [CrossRef]

56. Lavalley, J.C. Infrared spectrometric studies of the surface basicity of metal oxides and zeolites using adsorbed probe molecules. Catal. Today 1996, 27, 377-401. [CrossRef]

57. Leitner, N.K.V.; Berger, P.; Legube, B. Oxidation of Amino Groups by Hydroxyl Radicals in Relation to the Oxidation Degree of the $\alpha$-Carbon. Environ. Sci. Technol. 2002, 36, 3083-3089. [CrossRef]

58. Olanrewaju, J.; Newalkar, B.L.; Mancino, C.; Komarneni, S. Simplified synthesis of nitrate form of layered double hydroxide. Mater. Lett. 2000, 45, 307-310. [CrossRef] 